\title{
Three new species of Isospora Schneider, 1881 (Apicomplexa: Eimeriidae) from the double-collared seed eater, Sporophila caerulescens (Passeriformes: Emberizidae), from Eastern Brazil
}

\author{
Paulo Roberto de Carvalho Filho, Gisele Santos de Meireles + , Carlos Torres Ribeiro*, \\ Carlos Wilson Gomes Lopes/**/+
}

Curso de Pós-graduação em Ciências Veterinárias **Departamento de Parasitologia Veterinária, Instituto de Veterinária, UFRRJ, BR-465 Km 7, 23890-000 Seropédica, RJ, Brasil *Centro de Triagem de Animais Silvestres, Ibama, Horto Florestal Mário Xavier BR-465 Km 4, Seropédica, RJ, Brasil

Three isosporan species are described from the double-collared seedeater, Sporophila caerulescens from Eastern Brazil. Isospora sporophilae $n$. sp. oocysts spherical to subspherical; oocyst wall bi-layered, smooth, inner layer colorless to pale yellowish, $21.6 \times 20.9$ (19.20-23.20 × 18.40-22.60) $\mu$ m, shape-index $1.03 \pm 0.02$ (1-1.10), with no micropyle or oocyst residuum. Polar bodies splinter-like or comma-like. Sporocysts ovoidal, $15.2 \times 10.6$ (17.40$12.80 \times 12.60-8.40) \mu m$, shape-index $1.43 \pm 0.14$ (1.17-1.81), with knob-like Stieda body and residuum. Large crystalloid body in the center of the sporocyst. Isospora flausinoi $n$. sp. oocysts spherical to subspherical, oocyst wall bi-layered, smooth, colorless, $17.30 \times 16.53$ (14-20 × 13.60-20) $\mu \mathrm{m}$, shape-index $1.05 \pm 0.04$ (1-1.21). Micropyle and oocyst residuum absent; presence of a large polar body. Sporocyst piriform, $14.88 \times 10.70(11.80-18 \times 8-12.40)$ $\mu \mathrm{m}$, shape-index $1.40 \pm 0.18$ (1.07-1.77), with smooth, thin, single-layered wall. Sporocyst with rounded Stieda body with no substieda body, and residuum composed of granular material. Isospora teixeirafilhoi $n$. sp. oocysts spherical to subspherical, oocyst wall bi-layered, smooth, colorless, $17.41 \times 16.81$ (15.60 - 19.40 × 14.20-18.80) $\mu \mathrm{m}$. Shape-index $1.04 \pm 0.08$ (1-1.12). Micropyle and oocyst residuum absent; presence of a small double-lobuled polar body. Sporocyst ovoid, $11.74 \times 8.12(9-14.20 \times 6.20-9.40) \mu m$. Shape-index $1.46 \pm 0.23$ (1.06-1.88). Sporocyst with knob-like Stieda body, no sub-Stieda body and residuum composed of granular material.

Key words: Isospora sporophilae sp. n. - Isospora flausinoi sp. n. - Isospora teixeirafilhoi sp. n. - Sporophila caerulescens double-collared seedeater - Brazil

Sporophila caerulescens Vieillot (1823) (Passeriformes: Emberizidae) is a small bird widely distributed in semi-open and farmland areas of South America. They are found from Bolivia and Central Brazil to central Argentina (Souza 2002), and migrate northwards to Amazonia during the southern winter (Höfling \& Camargo 1993, Sick 1993). No species of Isospora has previously been described in emberizid birds of the genus Sporophila (Duszynski et al. 2004). This paper describes three new species of Isospora found infecting specimens of the double-collared seedeater Sporophila caerulescens that had been apprehended by Brazilian governmental authorities and sent to the Wildlife Screening Center in the state of Rio de Janeiro.

\section{MATERIALS AND METHODS}

Among specimens of $S$. caerulescens (Passeriformes: Emberizidae) that were quarentined at the Wildlife Screening Center in the municipality of Seropédica, state of Rio de Janeiro, Brazil, one male died and was necropsied. Intestines were removed, and their contents and intestinal

Financial support: CNPq, Faperj

${ }^{+}$Corresponding author. E-mail: lopescwg@ufrrj.br

${ }^{++}$Fellowship Pibic (CBNPq/UFRJ)

Received 29 September 2004

Accepted 24 February 2005 mucosa scrapings were suspended in a $2.5 \%(\mathrm{w} / \mathrm{v})$ aqueous $\mathrm{K}_{2} \mathrm{Cr}_{2} \mathrm{O}_{7}$ solution, placed into a Petri dish forming a thin layer of liquid $(\sim 5 \mathrm{~mm})$ and stored at laboratory temperature (at $20-24^{\circ} \mathrm{C}$ ) until oocyst sporulation. Oocysts were concentrated by flotation in Sheather's sugar solution (sp. g. 1.20) and examined under light microscopy following methods described by Duszynski and Wilber (1997). Observation on morphology, photomicrographs, and line-drawings were made with a Carl Zeiss, a JenapolZeiss Jena, and Wild M-20 respectively, using a $100 \times$ apochromatic oil immersion objective. All measurements, which were made with a GF-P16X ocular micrometer, are in $\mu \mathrm{m}$. Size ranges are in parentheses followed by means, standard deviations and shape index (lenght/width).

\section{RESULTS}

Isospora sporophilae $\mathrm{n}$. $\mathrm{sp}$.

Description - Sporulated oocysts are spherical to subspherical (Figs 1a, 2a, b, c), $21.61 \pm 1.18(19.20-23.20) \times$ $20.89 \pm 1.16(18.40-22.60)(n=50)$. Shape-index (length/ width) of $1.03 \pm 0.02$ (1-1.10). Wall bi-layered, inner layer colorless to pale yellowish, smooth, $1.26 \pm 0.18$ thick. Micropyle and oocyst residuum absent; splinter-like or comma-like polar bodies present, concentrated at the poles of the oocyst's longest axis. Sporocyst ovoid, $15.15 \pm$ $1.10(12.80-17.40) \times 10.65 \pm 0.86(8.40-12.60)(n=48)$, with smooth, thin, single-layered wall; shape-index of $1.43 \pm$ 0.14 (1.17-1.81). Sporocyst with small knob-like Stieda body but no sub-Stieda body; residuum composed of granular 
material dislocated to Stieda body pole. Presence of one well-defined crystaloid body in the center of the sporocyst. Sporozoites with refractile body at one end and compressed to the anti-Stieda body pole.

\section{Taxonomic summary}

Type host: Sporophila caerulescens (Vieillot 1823) (Aves: Passeriformes: Emberizidae), double-collared seedeater. Type material: oocysts in 10\% formaldehyde-saline solution deposited at the Parasitology Collection, in the Department of Animal Parasitology, UFRRJ, Seropédica, RJ, Brazil under repository number P-010/2004, including phototypes and line-drawings.

Type locality: unknown. Birds were apprehended in the state of Rio de Janeiro.

Time of sporulation: 1 week

Site of infection: unknown, oocysts recovered from intestinal content and mucosal scrapings.

Etymology: the specific name is derived from the generic name of the type host.

\section{Isospora flausinoi $\mathrm{n}$. sp.}

Description - Sporulated oocysts are spherical to subspherical (Figs 1b, 2d), $17.30 \pm 1.44(14-20.00) \times 16.53 \pm$ $1.25(13.60-20.00)(\mathrm{n}=50)$. Shape-index (length/width) 1.05 \pm 0.04 (1-1.21). Colorless, smooth, bi-layered wall, $1.02 \pm$ 0.18 thick. Micropyle and oocyst residuum absent; presence of a large polar granule. Sporocyst piriform, $14.88 \pm$ $1.47(11.80-18.00) \times 10.70 \pm 1.07(8-12.40)(n=48)$, with smooth, thin, single-layered wall; shape-index $1.40 \pm 0.18$ (1.07-1.77). Sporocyst with rounded Stieda body with no substieda body, and residuum composed of granular material in the middle of the sporocyst, surrounded by sporozoites. Sporozoites with refractile body at one end.

\section{Taxonomic summary}

Type host: Sporophila caerulescens (Vieillot 1823) (Aves: Passeriformes: Emberizidae), double-collared seedeater.

Time of sporulation: 1 week

Type material: oocysts in 10\% formaldehyde-saline solution deposited at the Parasitology Collection, in the Department of Animal Parasitology, UFRRJ, Seropédica, RJ, Brazil under repository number P-011/2004, including phototypes and line-drawings.

Type locality: unknown. Birds were apprehended in the state of Rio de Janeiro.

Site of infection: unknown, oocysts recovered from intestinal content and mucosal scrapings.

Etymology: the specific name is derived from the last name of our colleague Dr Walter Flausino, given in his honor for thirty years of work in the Department of Animal Parasitology of UFRRJ.

\section{Isospora teixeirafilhoi $\mathrm{n}$. sp.}

Description - Sporulated oocysts are spherical to subspherical (Figs 1c, 2e, f), $17.41 \pm 0.86(15.60-19.40) \times 16.81$ $\pm 1.01(14.20-18.80)(\mathrm{n}=50)$. Shape-index (length/width) of 1.04 \pm 0.08 (1-1.12). Colorless, smooth, bi-layered wall, $1.17 \pm 0.14$ thick. Micropyle and oocyst residuum absent; presence of a small double-lobuled polar body. This is
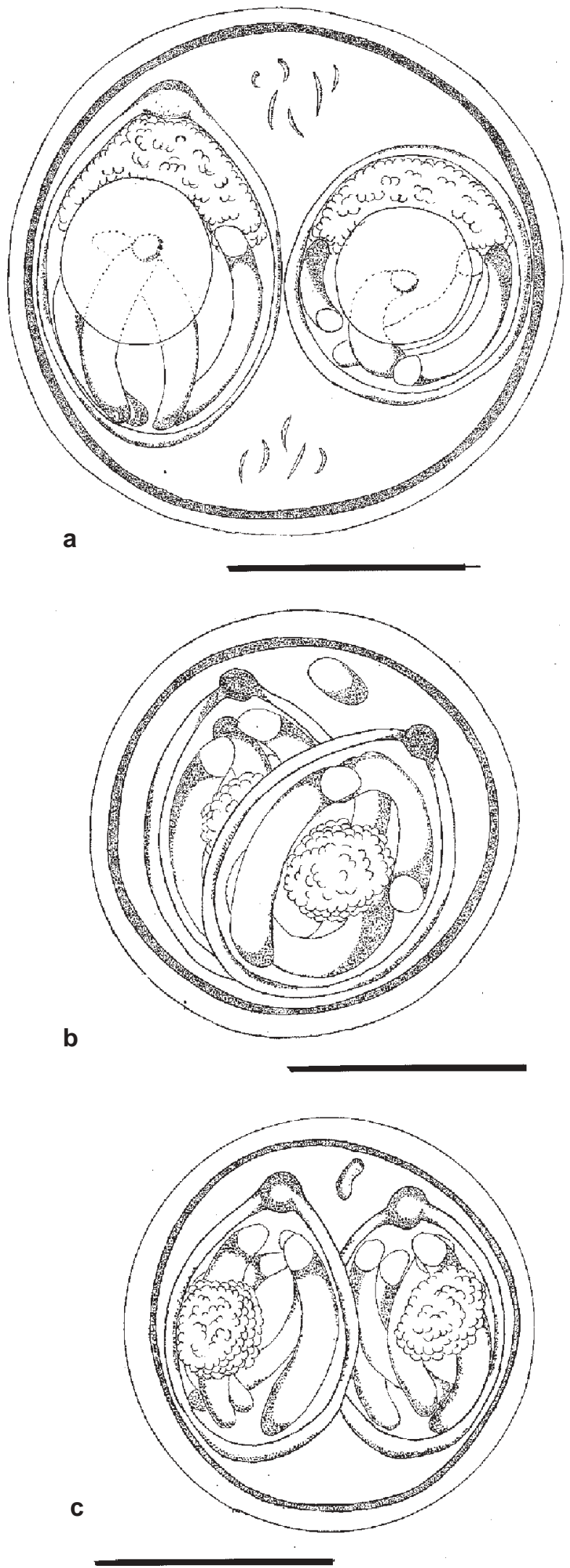

Fig. 1: line drawings of sporulated oocysts of new coccidia species recovered from the double-collared seedeater, Sporophila caerulescens. Scale bar $=10 \mu \mathrm{m}$. a: Isospora sporophilae $\mathrm{n}$. sp.; b: Isospora flausinoi n. sp.; c: Isospora teixeirafilhoi n. sp. 
often divided into two smaller polar bodies that remain close together. Sporocyst ovoid, $11.74 \pm 1.22(9-14.20) \times$ $8.12 \pm 0.81(6.20-9.40)(\mathrm{n}=50)$, with smooth, thin, singlelayered wall; shape-index of $1.46 \pm 0.23$ (1.06 -1.88). Sporocyst with knob-like Stieda body with no substieda body, and residuum composed of granular material. Sporozoites with refractile body at one end and disposed along the longests axis of the sporocyst.

\section{Taxonomic summary}

Type host: Sporophila caerulescens (Vieillot 1823) (Aves: Passeriformes: Emberizidae), double-collared seedeater.

Time of sporulation: $\sim 1$ week

Type material: oocysts in $10 \%$ formaldehyde-saline solution deposited at the Parasitology Collection, in the Department of Animal Parasitology, UFRRJ, Seropédica, RJ, Brazil under repository number P-012/2004, including phototypes and line-drawings.

Type locality: unknown. Birds were apprehended in the state of Rio de Janeiro.

Site of infection: unknown, oocysts recovered from intestinal content and mucosal scrapings.

Etymology: the specific name is in honor of our colleague Dr Walter Leira Teixeira Filho, with whom we have had the great satisfaction of working for so many years.

\section{DISCUSSION}

Although more than 70 species of Brazilian birds have been classified into the family Emberizidae (Souza 2002), only 13 Isospora species of emberizids birds have previously been well identified all over the world, and eleven of them are in American emberizid birds (Duszynski et al. 2004). I. vanriperorum (Levine et al. 1980, Levine 1982) was described from the northern cardinal Cardinalis cardinalis, which is not found in the same area as $S$. caerulescens. The sporocysts show morphological differences in the presence of a sub-Stieda body, which is absent in those of I. sporophilae, I. flausinoi, and I. teixeirafilhoi, and the oocysts are larger than those of $I$. flausinoi and I. teixeirafilhoi. Four of these species were found in material from birds that inhabit South American mainland: I. paroariae (Upton et al. 1985), I. pityli and I. formarum (McQuistion \& Capparella 1992), and I. tiaris (Ball \& Daszak 1997). Oocysts of I. paroariae, described in faeces of Paroaria coronata by Upton et al. (1985), differ completely from those described in this paper $(22.3$ $\times 21.4$ for oocysts of I. paroariae; larger than oocysts of I. flausinoi and I. teixeirafilhoi and, moreover, the sporocysts of $I$. paroariae have a sub-Stieda body which is absent in the presently described species). Three other species of Isospora were described in South American

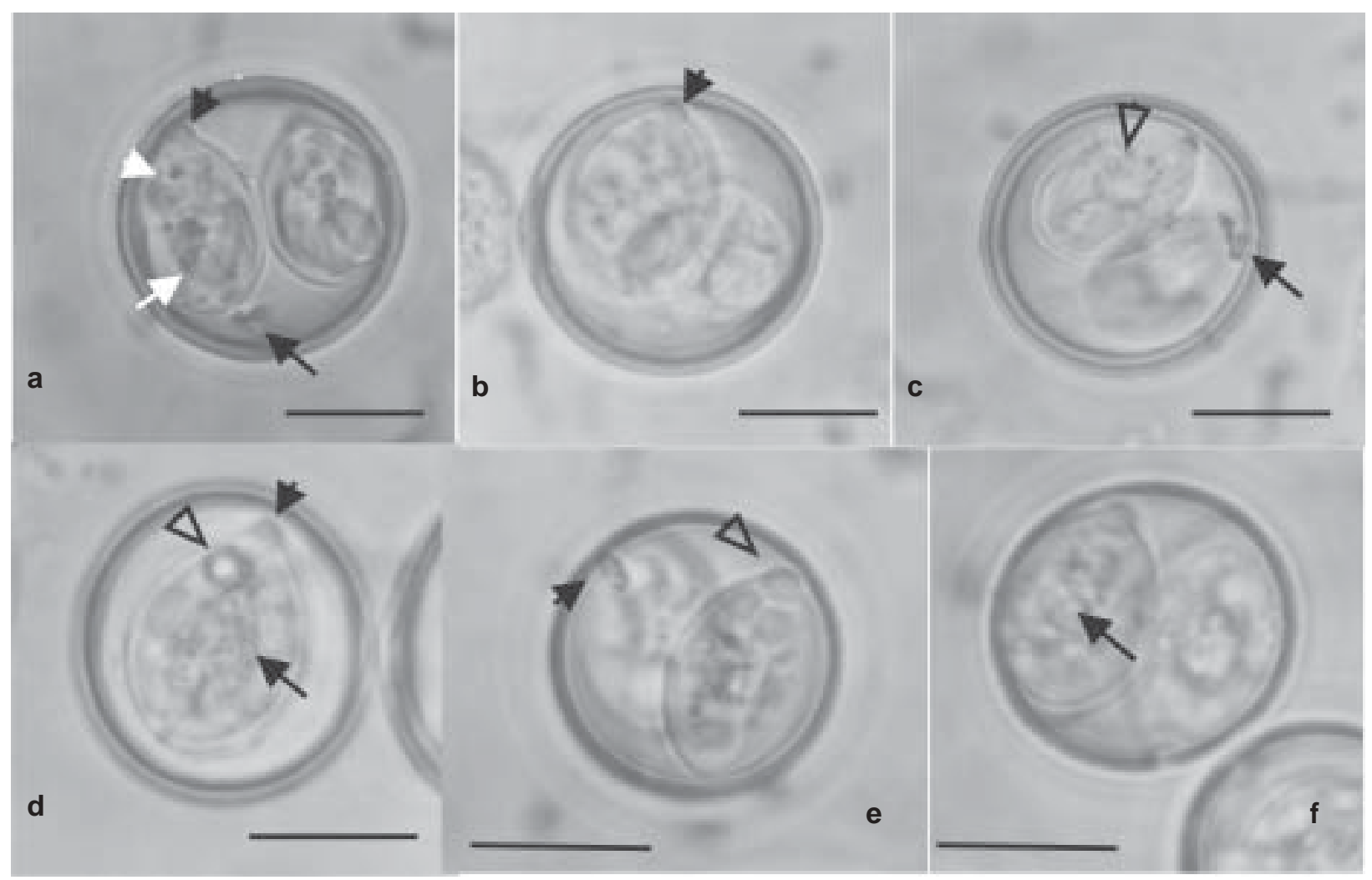

Fig. 2: photographs of oocysts of Isospora sporophilae (a, b, c), Isospora flausinoi (d), Isospora teixeirafilhoi (e, f), all in the same scale bar $=10 \mu \mathrm{m}$. Note knob-like Stieda body (a-b) (dark full arrowhead), sporocyst residuum dislocated to stiedal body pole (a) (white full arrowhead), sporozoites compressed to anti-Stieda body pole (a) (white arrow), splinter-like polar bodies condensed on oocyst length poles (a, c) (dark arrow) and a large crystalloid body in the center of the sporozoite (c) (empty arrowhead) for I. sporophilae. Rounded Stieda body (d) (dark arrowhead), residuum in the middle of the sporocyst (dark arrow) and large polar granule (empty arrowhead) for I. flausinoi and knob-like Stieda body (e, f) (empty arrowhead), polar granule (dark arrowhead) and sporocyst residuum (dark arrow) for I. teixeirafilhoi. 
emberizid birds. McQuistion and Capparella (1992) found the two species I. pityli and I. formarum in Pitylus grossus (Passeriformes: Cardinalinae). P. grossus and S. caerulescens are sympatric only in the southern winter, when S. caerulescens migrates to humid forests of the Amazon River basin (Höfling \& Camargo 1993, Sick 1993). The oocysts of $I$. pityli are subspherical, like those of $I$. sporophilae, but differ somewhat in the measurements $(20.1 \times 18.8$ for oocysts of $I$. pityli versus $21.6 \times 20.9$ for those of $I$. sporophilae; $14.7 \times 9.4$ for the sporocysts of $I$. pityli versus $15.2 \times 10.7$ for sporocysts of I. sporophilae). Oocysts of I. flausinoi and I. teixeirafilhoi are markedly smaller than I. pityli $(17.3 \times 16.5$ for oocysts of I. flausinoi and $17.4 \times 16.8$ for oocysts of I. teixeirafilhoi versus 20.1 $\times 18.8$ for oocysts of $I$. pityli) and, moreover, oocysts of I. formarum are larger $(24.6 \times 23.5)$ and have a large triangle-shaped sub-Stieda body which is absent in the presently described species. I. tiaris was described in Tiaris fuliginosa, an emberizid bird which is sympatric with $S$. caerulescens. Its oocysts are considerably larger $(27.1 \times$ 23.8, Ball \& Daszak 1997) than those of the three new species described in this paper, and sporocysts of I. tiaris have a sub-Stieda body which differentiates the oocyst of this parasite from those of the three new presently described species. Finally, six species of Isospora were described in finches Camarhynchus parvulus and Geospiza fortis from Galapagos Islands (McQuistion \& Wilson 1988, 1989, McQuistion 1990). The presence of a sub-Stieda body in the sporocysts of I. exigua, I. rotunda, I. fragmenta, and I. temeraria of C. parvulus, and I. daphnensis and I. geospizae from Geospiza fortis differentiates these parasites from the sporocysts of the three presently described species. In size, the oocysts of the Galapagos also differ: some are considerably larger, while others are smaller. Geographic isolation of the archipelago from the mainland of South America is considered to be a segregation factor for species of Isospora in insular and mainland emberizid birds (McQuistion \& Capparella 1992).

\section{REFERENCES}

Ball SJ, Daszak P 1997. Isospora tiaras n. sp. (Apicomplexa: Eimeriidae) from the sooty grassquit (Tiaris fuliginosa), a passeriform bird of South America. J Parasitol 83: 465466.

Duszynski DW, Wilber PG 1997. A guideline for the preparation of species descriptions in the Eimeriidae. $J$ Parasitol 83: 333-336.

Duszynski DW, Upton SJ, Couch L 2004. The Coccidia of the World. www.biology.unm.edu/biology/coccidia/home.html/ Updated on 21 February 2004. Accessed on 25 August 2004.

Höfling E, Camargo HFA 1993. Aves no Campus, Instituto de Biociências da Universidade de São Paulo, São Paulo, 209 pp.

Levine ND 1982. Isospora vanriperorum n. nom. for $I$. cardinalis Levine, Van Riper \& Van Riper, 1980, preoccupied. J Protozool 29: 653.

Levine ND, Van Riper S, Van Riper C 1980. Five new species of Isospora from Hawaiian birds. J Protozool 27: 258-259.

McQuistion TE 1990. Isospora daphnensis n. sp. (Apicomplexa: Eimeriidae) from the medium ground finch (Geospiza fortis) from the Galapagos Island. J Parasitol 76: 30-32.

McQuistion TE, Capparella A 1992. Two new coccidian parasites from the slate-colored grosbeak (Pitylus grossus) of South America. J Parasitol 78: 805-807.

McQuistion TE, Wilson M 1988. Four new species of Isospora from the small tree finch (Camarhynchus parvulus) from the Galapagos Island. J Protozool 35: 98-99.

McQuistion TE, Wilson M 1989. Isospora geospizae, a new coccidian parasite (Apicomplexa: Eimeriidae) from the small ground finch (Geospiza fuliginosa) and the medium ground finch (Geospiza fortis) from the Galapagos Island. System Parasitol 14: 141-144.

Sick H 1993. Birds in Brazil, A Natural History, Princeton University Press, Princeton, 703 pp.

Souza D 2002. All the Birds of Brazil: An Identification Guide, Editora Dall, Feira de Santana, 356 pp.

Upton SJ, Current WL, Clubb SL 1985. Two new species of Isospora (Apicomplexa: Eimeriidae) form passeriform birds of South America. System Parasitol 7: 227-229. 